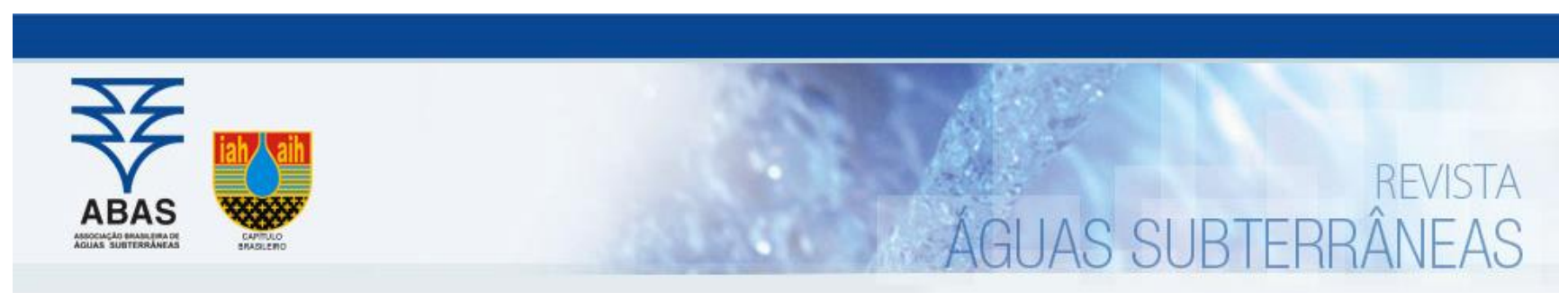

Artigos

\title{
Análise do impacto potencial de áreas com contaminação de solos sobre cursos d'água e poços no município de São Paulo
}

\author{
Analysis of the potential impact of areas with soil contamination on \\ watercourses and wells in São Paulo
}

\author{
Nathalia Banharoto Dutra da Silva1; Isabella Borges ${ }^{1}$; Vitor Vieira Vasconcelos ${ }^{1} \bowtie$ \\ 1 Universidade Federal do ABC (UFABC), Santo André, SP \\ $\llbracket$ nathaliabanharotodutra@gmail.com, isabellaborges19@hotmail.com, vitor.v.v@gmail.com
}

Palavras-chave:

Áreas contaminadas.

Águas subterrâneas.

Poluição.

Hidrogeologia.

Recursos hídricos.

Keywords:

Contaminated áreas.

Groundwater.

Pollution.

Hydrogeology.

Water resources.

Revisão por pares.

Recebido em: 27/11/2019.

Aprovado em: 31/07/2020.

Resumo

Este artigo tem como objetivo identificar corpos hídricos e poços no Município de São Paulo sob risco relativo à proximidade áreas de solos contaminados. Foram traçados raios de segurança entre as áreas contaminadas e os potenciais alvos de contaminação, conforme as características hidrogeológicas dos aquíferos. Assim, foi possível determinar interseções com rios e poços, mapeando-os como sob risco de contaminação. Em seguida, produziu-se um mapa de im pacto acumulado da poluição na hidrografia, traduzindo a topologia hidrológica levando em consideração os potenciais pontos de contaminação à montante. Também foi mapeada a vulnerabilidade dos lençóis freáticos à contaminação, por meio de um índice de vulnerabilidade de aquíferos que considera a condutividade hidráulica e a profundidade da camada não saturada do aquífero. 49 poços (1,68\%) apresentaram potencial de contaminação, sendo que $65,31 \%$ deles são declarados como de abastecimento humano, e localizam-se predominantemente em áreas com alta densidade popula-cional e vulnerabilidade extremamente alta de contaminação dos aquíferos. Nesse contexto, contribuiuse para análise da situação dos recursos hídricos de São Paulo, para que usuários e o poder público possuam ciência dos riscos de contaminação e, assim, priorizar as medidas preventivas quanto a esses riscos.

Abstract

The aim of this paper is to identify water bodies and wells at risk related to the proximity of contaminated soil areas in the city of São Paulo. Safety circles were traced between the contaminated areas and the potential contamination targets according to the hydrogeological characteristics of the aquifers. Thus, it was possible to determine intersections with rivers and wells, mapping them as under risk of contamination. A map of the accumulated impact of pollution on the hydrography was produced, according to the hydrological topology, taking into consideration the potential upstream contamination points. The groundwater vulnerability to contamination was also mapped, through an Aquifer Vulnerability Index (AVI) that takes into account the hydraulic conductivity and the unsaturated depth of the aquifer. Forty-nine wells $(1.68 \%)$, of which $65.31 \%$ are categorized for human drinking supply, have a potential risk of contamination. These are located predominantly in areas of high population density and extremely high vulnerability to aquifer contamination. The results contributed to the analysis of water resources in São Paulo, in order that users and public authorities could be made aware of the risks of contamination and could prioritize preventive measures regarding these risks.

DOI: http:/dx.doi.org/10.14295/ras.v34i3.29753

\section{INTRODUÇÃO}

A partir da metade do século XX aumentou a consideração quanto aos impactos das ações humanas sobre o ambiente. $A$ aceleração do desenvolvimento científico e tecnológico, urbanização e adensamento populacional intenso resultou em crescentes problemas de saúde decorrentes de efeitos ambientais negativos. Com isso se percebeu cada vez mais uma maior interdependência entre saúde e fatores ambientais, especialmente no que diz respeito à saúde pública (BRILHANTE e CALDAS, 1999).

Nesse contexto, muitos poluentes resultantes da atividade hu- mana estão sendo descartados no solo há gerações e podem ter graves impactos na saúde humana. Os principais poluentes são provenientes dos usos urbanos, industriais e da agricultura. As fontes mais comuns da poluição e contaminação podem ser classificas em seis categorias, sendo elas (CETESB, GTZ, 2001, FETTER, 1993):

- Fontes projetadas para descarga de substâncias no subsolo, como é o caso de tanques sépticos e fossas negras;

- Fontes projetadas para armazenar, tratar e/ou dispor substâncias no solo, incluídas as áreas de disposição de 
resíduos;

- Fontes projetadas para reter substâncias durante o seu transporte, como oleodutos, tubulações para o transporte de esgoto e efluentes industriais;

- Fontes utilizadas para descarregar substâncias como consequência de atividades planejadas, por exemplo atividades agrícolas (irrigação, fertirrigação, aplicação de pesticidas e fertilizantes) e percolação de poluentes atmosféricos;

- Fontes que funcionam como um caminho preferencial para que os contaminantes entrem em um aquífero, como, por exemplo, poços de produção de petróleo e poços de monitoramento com falhas de construção e projeto;

- Fontes naturais ou fenômenos naturais associados às atividades humanas.

O município de São Paulo apresenta, ao longo de sua história de ocupação do solo, mais de 11.000 casos de contaminação de solos, em virtude dos efluentes de indústrias instaladas, vazamentos de postos de combustíveis e acidentes ambientais (HABERMANN e GOUVEIA, 2014). A contaminação do solo em um ponto específico do tecido urbano pode se estender pelo aquífero subterrâneo e alcançar corpos hídricos, estendendo seus efeitos nocivos à saúde humana. Os principais contaminantes dessas áreas são solventes halogenados, metais, hidrocarbonetos totais de petróleo, em específico solventes aromáticos, hidrocarbonetos policíclicos aromáticos e combustíveis automotivos (Santos et al., 2008). Segundo CETESB (2020), muitos desses contaminantes são classificados como cancerígenos, prováveis e possíveis cancerígenos pela Agência Internacional de Pesquisa em Câncer (IARC), e mesmo aqueles que não são classificados quando a carcinogenicidade podem causar doenças respiratórias, cardiovasculares, efeitos adversos quando expostos no pré-natal como diminuição da fertilidade e impacto no desenvolvimento como diminuição do peso ao nascer, dados na habilidade cognitiva, aumento de problemas de atenção, ansiedade, depressão e aumento de abortos espontâneos.

Existem vários fatores que influenciam no transporte de um poluente. Esse transporte se dá pelo fluxo no qual está dissolvido, sendo assim, a solubilidade desse poluente é importante pois se ele for inerte, o transporte terá a velocidade média do solvente e na direção das linhas de fluxo (DYMINSKI, 2006). Outras características do contaminante que intervêm no transporte são sua densidade e concentração. Nesse aspecto, técnicas de descontaminação do solo que aumentem a solubilidade dos contaminantes podem aumentar a velocidade e magnitude da contaminação dos aquíferos.

Outro fator que influencia no transporte dos poluentes é o solo, por meio dos processos de adsorção físico-química e de degradação bioquímica dos compostos percolantes (SOUZA, 2009). Dessa forma, o solo retém o contaminante, diminuindo sua velocidade à frente de contaminação, fenômeno chamado retardamento da frente de contaminação e que depende especialmente de sua granulometria, mineralogia da fração argila, permeabilidade e quantidade de matéria orgânica (DYMINSKI, 2006). Durante o período de retenção no solo, outros processos como biodegradação, volatilização e decaimento radioativo podem gradualmente diminuir o potencial de contaminação.

No que se refere especificamente à contaminação de aquíferos, fatores hidrogeológicos, tais como potencial de recarga ao aquífero, condutividade hidráulica do meio, o gradiente hidráulico e a porosidade, e também a profundidade do nível d'água, influenciam significativamente o deslocamento dos poluentes (GUIGUER, KOHNKE, 2002). Após atingir o nível freático, a pluma de poluição será então carreada para outras regiões, através do fluxo dessas águas podendo atingir poços e outras captações de água subterrânea, devido as intersecções existentes nos aquíferos (SOUZA, 2009). Uma vez poluídas ou contaminadas, as águas subterrâneas demandam um elevado dispêndio de recursos financeiros para sua remediação (ANA, 2007).

A CETESB possui, como base de dados divulgada em seu portal, o cadastro de áreas contaminadas (CETESB, 2019), atualizada anualmente.

Levando em consideração a diversidade de fatores de interferência necessários para analisar e determinar quais poços e corpos hídrico estão em risco de contaminação, uma maneira simplificada de análise preliminar de risco é a delimitação de raios de prevenção. 0 raio de prevenção tem como base o raio de alerta estabelecido no Decreto Estadual $n^{\circ} 32.955$, de 1991, sobre as áreas de proteção. Segundo o Art. 25 desse decreto: "Serão estabelecidos, em cada caso, além do Perímetro Imediato de Proteção Sanitária, Perímetros de Alerta contra poluição, tomando-se por base uma distância coaxial ao sentido do fluxo, a partir do ponto de captação, equivalente ao tempo de trânsito de cinquenta dias de águas no aquífero, no caso de poluentes não conservativos."

Este estudo, tem como objetivo geral determinar quais áreas contaminadas devem ser priorizadas a remediação, analisando o potencial impacto das áreas com contaminação do solo sobre poços e corpos hídricos no município de São Paulo. Neste intento, define o risco a partir do raio de alerta, que foi determinado a partir de interpolação da vazão de estabilização por krigagem indicativa, além de mapear o acúmulo do risco de poluição sobre a hidrografia. Considerouse na análise a vulnerabilidade à contaminação das águas subterrâneas do município de São Paulo, cuja determinação foi realizada utilizando o método AVI (Aquifer Vulnerability Index - Índice de Vulnerabilidade do Aquífero), onde os dois parâmetros, vazão de estabilização e condutividade hidráulica, também foram interpolados, dessa vez, por krigagem ordinária comparando-o enfim à exposição da população à contaminação.

\section{METODOLOGIA}

\subsection{Caracterização da área de estudo}

A área de estudo compreende o munícipio de São Paulo, que em 2017 representava 36\% das áreas contaminadas e reabilitadas no Estado de São Paulo (CETESB, 2017). Está localizado no sudeste do Estado de São Paulo e apresenta 32 subprefeituras (figura 1). Segundo o IBGE (2019), possui área 
de $1.521,110 \mathrm{~km}^{2}$ (2018) e população estimada em 12,2 milhões de habitantes em 2019. As rochas do aquífero sedimentar de São Paulo, sob o qual está o município, pertencem às seguintes unidades litológicas: (1) Grupo Taubaté (Paleógeno) constituído, da base para o topo, pelas formações Resende (arenitos, conglomerados, diamictitos e lamitos), Tremembé (argilitos, folhelhos, margas e calcários dolomíticos) e São Paulo (arenitos, argilitos, siltitos e arenitos conglomeráticos); (2) Formação Itaquaquecetuba (arenitos grossos arcoseanos, lamitos e brechas) (Neógeno); e (3) coberturas aluvionares e coluvionares (Quaternário) (RICCOMINI \& COIMBRA 1992). De acordo com Rocha et al. (2006), a espessura média do aquífero é de 100 metros, podendo em algumas áreas atingir mais de $250 \mathrm{~m}$ de profundidade. Abaixo do aquífero São Paulo estão litologias de rochas fraturadas do embasamento cristalino pré-cambrianos (PACHECO, 1984).

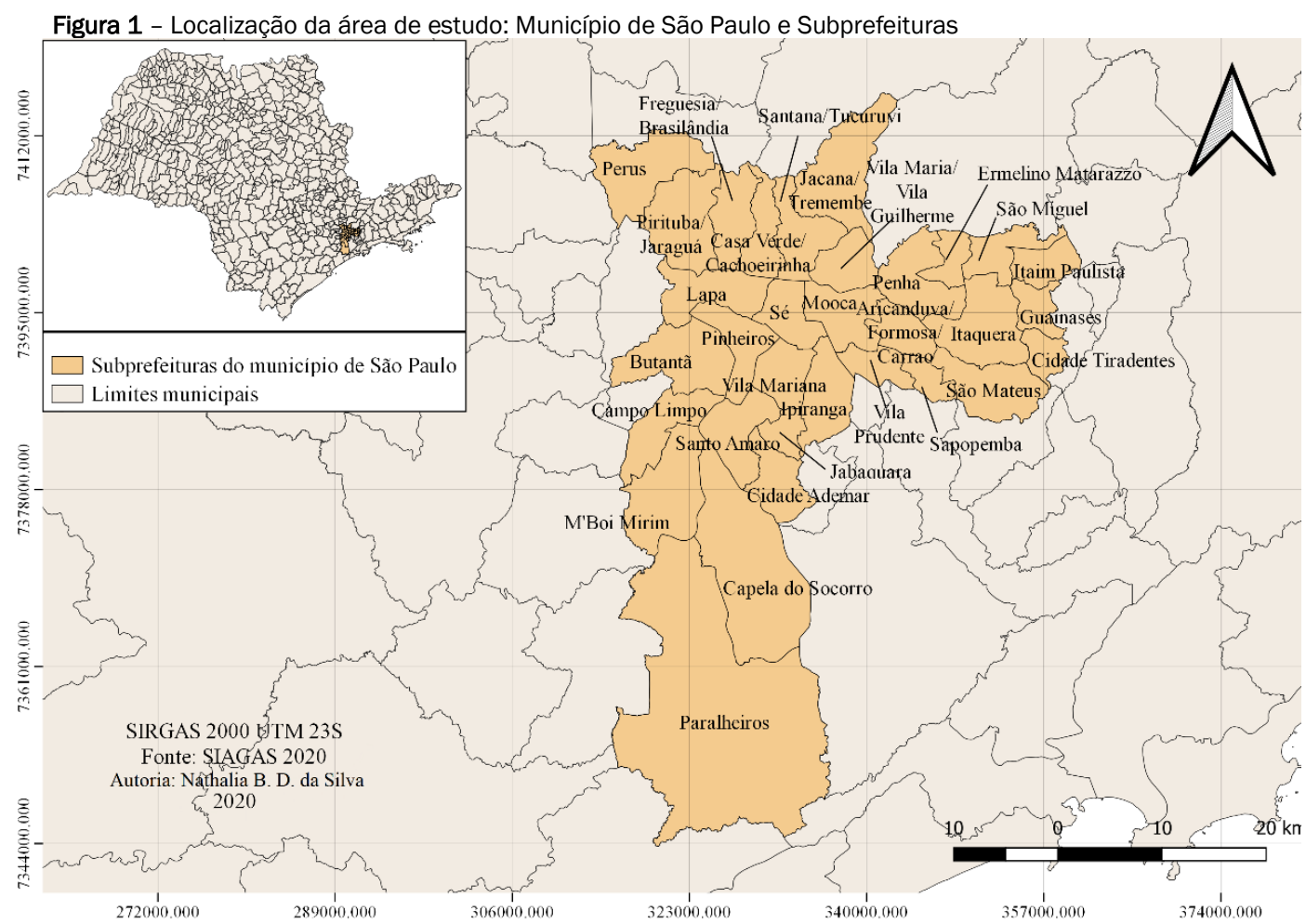

Fonte: Autores (2020)

\subsection{Base de dados}

Este estudo foi desenvolvido com base nos dados oferecidos pela CETESB, relativos a pontos de contaminação solo. A 1. A mesma secretaria também disponibiliza a base espacial de hidrografia em escala de detalhe para o município, bem como os limites administrativos do município e do estado de São Paulo. A localização e as características dos poços de água foram obtidas por meio do sistema SIAGAS, mantidos pelo Serviço Geológico Brasileiro (CPRM)².

A fim de analisar à exposição da população ao risco de contaminação, foi elaborado um mapa de densidade populacional utilizando os dados censitários de 2010 do IBGE ${ }^{3}$ disponibilizados por grade estatística (IBGE, 2016).

\subsection{Análise estrutural dos dados geográficos}

A estrutura de correlação espacial dos dados de poços no sistema SIAGAS foi analisada por meio de semivariogramas. Através do semivariograma, estimador geoestatístico da depen-
Secretaria do Verde e Meio Ambiente do município de São Paulo compila esses dados para o município e disponibiliza abertamente o arquivo georreferenciado com sua localização dência espacial dos dados, que se encontraram os pesos ótimos utilizados para interpolar os valores quando associado às amostras existentes por meio da interpolação por krigagem. 0 semivariograma experimental de cada variável de interesse foi determinado para cada valor de $h$ (distância entre pares de pontos) considerando todos os pares de amostras $z(x)$ e $z(x+h)$, separadas pelo vetor distância $h$, a partir da equação 1 (CAMARGO et al., 2004):

$$
\hat{\gamma}(h)=\frac{1}{2 N(h)} \sum_{i=1}^{N(h)}\left[z\left(x_{i}\right)-z\left(x_{i}+h\right)\right]^{2}
$$

Onde:

$\hat{\gamma}(h)$ é o semivariograma estimado

\footnotetext{
${ }^{1}$ Disponível em: www.cetesb.sp.gov.br/areas-contaminadas/, acesso em: 13 jul. 2020.

${ }^{2}$ Disponível em http://siagasweb.cprm.gov.br/layout/, acesso em: 10 dez. 2018.

${ }^{3}$ Disponível em https://censo2010.ibge.gov.br/, acesso em: 6 jul. 2020.
} 
$\mathrm{N}(\boldsymbol{h})$ é o número de pares de valores medidos.

o gráfico de $\hat{\gamma}(h)$ versus $h$ indicou como a amostras se correlacionam. Os parâmetros observados no semivariograma e utilizados para realização da krigagem foram (CAMARGO, 1998): o alcance, que é a distância dentro da qual as amostrar apresentam-se correlacionadas espacialmente, e que corresponde visualmente ao valor em que o semivariograma se estabiliza; o patamar, que é o valor do eixo vertical do semivariograma correspondente a seu alcance; e o efeito pepita, que por sua vez é o valor da semivariância quando a distância tende a zero e representa a variação residual e aleatória.

\subsection{Interpolação dos dados}

A interpolação espacial foi realizada a fim de estimar valores de variáveis de interesse onde não se tem informação. Existem vários modelos de interpolação, podendo ser diferenciados quanto à abordagem. Dentre os métodos de interpolação espacial existentes, optou-se por utilizar os de krigagem, por levarem em consideração a estrutura de correlação espacial dos dados espaciais por meio de semivariogramas, calibrada por validação cruzada, permitindo assim uma maior confiabilidade (OLIVER; WEBSTER, 2015). A krigagem incorpora a variação espacial na interpolação, com o objetivo de gerar uma superfície de estimação não tendenciosa, acompanhada de uma superfície auxiliar de desvio padrão que aponta para a incerteza de predição em cada local mapeado (YAMAMOTO; LANDIM, 2013). Além disso, devido à grande variação espacial dos dados referentes a água subterrânea, a krigagem destaca-se por ser um método não-determinístico, que, ao modelar também a magnitude ideal efeito pepita (nugget), cria uma superfície de interpolação suavizada com melhor capacidade de previsão dos resultados (MONTÉS, 1994). A krigagem tem sido amplamente utilizada na interpolação de dados de água subterrânea, com resultados satisfatórios, se comparados a outros métodos (GUNDOGDU; GUNEY, 2007; AHMADI e SEGHAMIZ; 2008; MOSLEMZADEH et al., 2011; VASCONCELOS et al., 2017).

Existem diversos métodos de krigagem, dentre os quais foram utilizadas neste artigo a krigagem ordinária, que busca predições ótimas da variável em estudo, em locais não observados, minimizando a variância do erro associado a essa estimativa; e a krigagem indicativa que servem indica a probabilidade, em cada local mapeado, de a variável de referência exceder um limiar especificado (FELGUEIRAS et al., 2004).

\subsection{Validação dos resultados}

Foi empregada a validação cruzada para avaliar o quanto os modelos estatísticos de interpolação se adequaram aos fenômenos estudados, ou seja, se os modelos preveem os valores desconhecidos com maior ou menor precisão. Nas técnicas de interpolação espacial, a validação cruzada omite sequencialmente um ponto e prediz seu valor usando o restante dos dados, depois compara os valores previstos e amostrados. Essa análise é repetida retirando cada um dos pontos amostrados. Ao fim, os erros obtidos em cada ponto são avaliados de forma conjunta, construindo indicadores de qualidade de predição.

Várias medidas estatísticas foram utilizadas para avaliar o desempenho do modelo. Para um modelo que fornece previsões precisas, procurou-se modelos de interpolação com o erro médio próximo de zero, o valor da raiz do erro médio quadrado e a média do erro predito padrão sendo o menor possível e o valor da raiz média quadrática padronizada próximo de 1 (JOHNSTON et al., 2001).

\subsection{Determinação do raio de segurança}

O Instituto Geológico (2010) propôs raios de segurança para proteção de corpos de água de contaminantes subterrâneos do Estado de São Paulo. No presente estudo, esses raios foram delimitados a partir das áreas de solos contaminados no município de São Paulo, para com isso observar e marcar onde correm intersecção com poços e corpos hídricos da cidade. 0 raio adotado foi de $30 \mathrm{~m}$ a $50 \mathrm{~m}$ dependendo da vazão dos poços, conforme proposto pelo Instituto Geológico (2010) para o aquífero sedimentar São Paulo, no qual se localiza o município de São Paulo, seguindo as especificações do Decreto Estadual $n^{\circ} 32.955$, de 1991, que delimita os perímetros de proteção. A vazão de até $20 \mathrm{~m}^{3} / \mathrm{h}$ demanda 30 metros de raio, ao passo que a vazão acima de $20 \mathrm{~m}^{3} / \mathrm{h}$ necessita de 50 metros de raio.

Para os dados de vazão de estabilização usada para determinar o raio de segurança o semivariograma foi processado pelo complemento Geoestatiscal Analyst do software ArcGis 10.6, e os seus parâmetros foram calibrados automaticamente, com posterior avaliação visual do semivariograma e iteração manual dos valores de máximo e mínimo de vizinhos e também o setores de vizinhança foram trocados até encontrar o que resultou no melhor semivariograma com o menor valor da raiz do erro médio quadrado obtido por validação cruzada.

A partir do semivariograma foi realizada a interpolação espacial por krigagem indicativa dos dados de vazão de estabilização dos poços na região de estudo utilizando o mesmo complemento do software ArcGis 10.6. Essa krigagem indicativa nos informa quais áreas no município têm maior probabilidade de conter poços com vazão acima de $20 \mathrm{~m}^{3} / \mathrm{h}$. O raster interpolado final foi reclassificado a partir da Equação 2:

$\mathrm{R}=30+($ prob $* 20)$

onde:

\section{$R$ é o raio}

prob é a probabilidade da vazão do poço ser acima de $20 \mathrm{~m}^{3} / \mathrm{h}$.

Quando prob igual a zero, a vazão é menor ou igual a $20 \mathrm{~m}^{3} / \mathrm{h}$ e, portanto, o raio estabelecido é de 30 metros; já quando a prob é igual a um, a vazão é com certeza maior que $20 \mathrm{~m}^{3} / \mathrm{h}$ e o raio estabelecido é de 50 metros. Em valores intermediários de prob (entre 0 e 1), o raio aumenta gradualmente (de 30 a 50 metros). Trata-se de um aprimoramento da metodologia proposta pelo Instituto Geológico (2010), pois cria-se uma gradação dos raios com base na avaliação da incerteza 
quanto à vazão dos poços. Dessa forma, estabeleceu-se qual seria a distância mínima de segurança para cada área contaminada e criado em buffer, com raio de 30 metros a 50 metros dependendo da classificação anterior.

Para tanto, primeiro foi necessário transferir para a base vetorial das áreas contaminadas o valor encontrado na krigagem dos dados de vazão. Nesse caso, foi utilizado o complemento Point Sampling Tool no QGIS. Feito isso, analisou-se qual seria a probabilidade de a vazão de um poço estar acima de $20 \mathrm{~m}^{3} / \mathrm{h}$ no ponto central de cada uma das áreas contaminadas. Com isso, determinou-se o raio de segurança de cada uma dessas áreas por meio da Equação 1, adicionando esse raio à tabela de atributos da base vetorial de áreas contaminadas. Em seguida, criou-se o buffer de raio igual ao valor obtido pela respectiva equação.

A partir desses fundamentos, foram elaborados mapas para visualização dos pontos contaminados que intersectam corpos hídricos e poços, determinando-os como sob risco de contaminação. Sobre a rede hidrográfica, foi mapeado o potencial acumulação de poluição sobre a hidrografia, conectando topologicamente os trechos de rios de acordo com o número de áreas potencialmente contaminantes à montante.

\section{7. Índice de Vulnerabilidade}

A vulnerabilidade dos lençóis freáticos à contaminação do solo foi calculada a partir do método A.V.I. (Aquifer Vulnerability Index - Índice de Vulnerabilidade do Aquífero) (Van Stempvoort et al., 1992) pelo software R. Esse método baseia-se em dois parâmetros físicos: Espessura da camada sedimentar acima da zona saturada superfície a condutividade hidráulica.

O parâmetro relacionado à espessura da camada sedimentar causa influência na trajetória de infiltração da água até que o aquífero seja atingido. Quanto maior a espessura, mais tempo é exigido nesse percurso e a probabilidade do fluido se decompor aumenta, reduzindo a vulnerabilidade do aquífero e viceversa. De forma a compatibilizar com as informações da base de dados do SIAGAS, foi utilizada a informação do "nível estático" substituiu este parâmetro, isso porque se refere à altura da água quando não influenciada por bombeamento (Companhia de Pesquisa de Recursos Minerais-CPRM). Reconhece-se que nem sempre estes valores seriam equivalentes, visto que podem existir casos de poços jorrantes, ou nos quais os aquíferos explotados estão sobrepostos. Todavia, neste último caso, a informação do nível estático ainda é coerente, pois o indicador final de vulnerabilidade se ajusta à profundidade do aquífero que está sendo efetivamente explotado (quanto mais profundo, menos vulnerável).

A condutividade hidráulica, por sua vez, pode ser entendida como a facilidade com que uma litologia permite a percolação (vazão) de fluido (CABRAL, 2008). Sendo assim, altos valores de condutividade hidráulica, consequentemente, aumentam a vulnerabilidade do aquífero. A condutividade hidráulica pode ser estimada a partir de outros parâmetros indicados pela Equação 3 (ABGE, 1996):

condutividade hidráulica $=\frac{\text { vazão de estabilização }}{\left(5,5 \times(\text { nivel dinâmico }- \text { nível estático }) \times \frac{\text { diâmetro "mm" }}{2000}\right)}$

Baseado nestes parâmetros, calcula-se a resistência hidráulica, que é em si o Índice de Vulnerabilidade dos Aquíferos, de acordo com a Equação 4:

$$
\text { resistência hidráulica }=\frac{\text { nivel estático }}{\text { condutividade hidráulica }}
$$

A relação de referência entre a vulnerabilidade e a resistência hidráulica se dá pela Tabela 1 (VAN STEMPVOORT, EWERT, WASSENAAR, 1992).

Tabela 1 - Classes de Vulnerabilidade do método AVI.

\begin{tabular}{cc}
\hline Resistência Hidráulica (dias) & Classe de Vulnerabilidade \\
\hline $0-10$ & Extremamente Alta \\
$10-100$ & Alta \\
$100-1000$ & Moderada \\
\hline
\end{tabular}

Valores elevados de resistência indicam que o fluido demorou para atingir o aquífero e, portanto, a vulnerabilidade deste é menor do que daqueles que apresentaram baixo valor de resistência.

Para classificar a vulnerabilidade do aquífero foi primeiro calculado a condutividade hidráulica para os poços com informações disponíveis no SIAGAS, a partir da Equação 3. Como o intuito é determinar a vulnerabilidade em toda área do município de São Paulo, foi necessário executar a interpolação, nesse caso por krigagem ordinária, tanto da condutividade hidráulica quando no nível estático. Essas duas krigagens foram realizadas no software $\mathrm{R}$ por, com prévia normalização ordenada por quantil (Peterson e Cavanaugh, 2019), com pacote bestNormalize, e ajuste de semivariograma por validação cruzada com o pacote Automap (Hiemstra, 2015) de forma a reduzir a raiz do erro médio quadrado, e posteriormente foram retransformados para a escala original.
Já com os dados interpolados determinou-se a resistência hidráulica a partir da Equação 3, por meio da divisão de uma camada raster pela outra.

Os procedimentos adotados estão sumarizados a seguir:

- Krigagem indicativa da vazão dos poços com limiar de $20 \mathrm{~m}^{3} / \mathrm{h}$

- Localização dos pontos de contaminação pela malha do município;

- Estabelecimento de raios (buffers) de contaminação, ao redor desses pontos;

- Estabelecimento de intersecções: com pontos cujo raio alcança corpos hídricos ou poços de abastecimento

- Determinação de onde ocorrem as intersecções com corpos hídricos ou poços de abastecimento como 
potencialmente contaminados;

- Determinação e interpolação da condutividade hidráulica dos poços;

- Interpolação do nível estático dos poços para estimar a profundidade do lençol freático;

- Cálculo da resistência hidráulica;

- Análise topológica dos rios potencialmente contaminados, demonstrando a acumulação de poluição sobre a hidrografia;

- Cálculo da densidade demográfica a partir dos atributos de população e área.

\section{RESULTADOS E DISCUSSÃO}

As bases de dados com os resultados deste estudo encontram-se disponíveis

em:

https://app.box.com/s/1bkyzq50qyessntk915v4doxhn9npdn8 .

Os semivariogramas utilizados para a interpolação espacial por krigagem, com seus respectivos parâmetros, estão nas Figuras 2 a 4. Nota-se que o alcance do semivariograma para a vazão de estabilização é muito mais curto do que para a o nível estático e para a condutividade hidráulica. Todos os três semivariogramas apresentaram efeito pepita elevado em relação à semivariância do patamar, indicando uma grande variação em pontos próximos, que leva à necessidade de uma superfície de interpolação suavizada (MONTÉS, 1994). O mapa da Figura 5 apresenta o mapa da krigagem ordinária com os dados de vazão de estabilização dos poços na região de estudo para determinar o raio da área de segurança de cada ponto de contaminação. E o desvio padrão dessa interpolação é apresentado na figura 6 .

Figura 2 - Semivariograma da vazão de estabilização 4

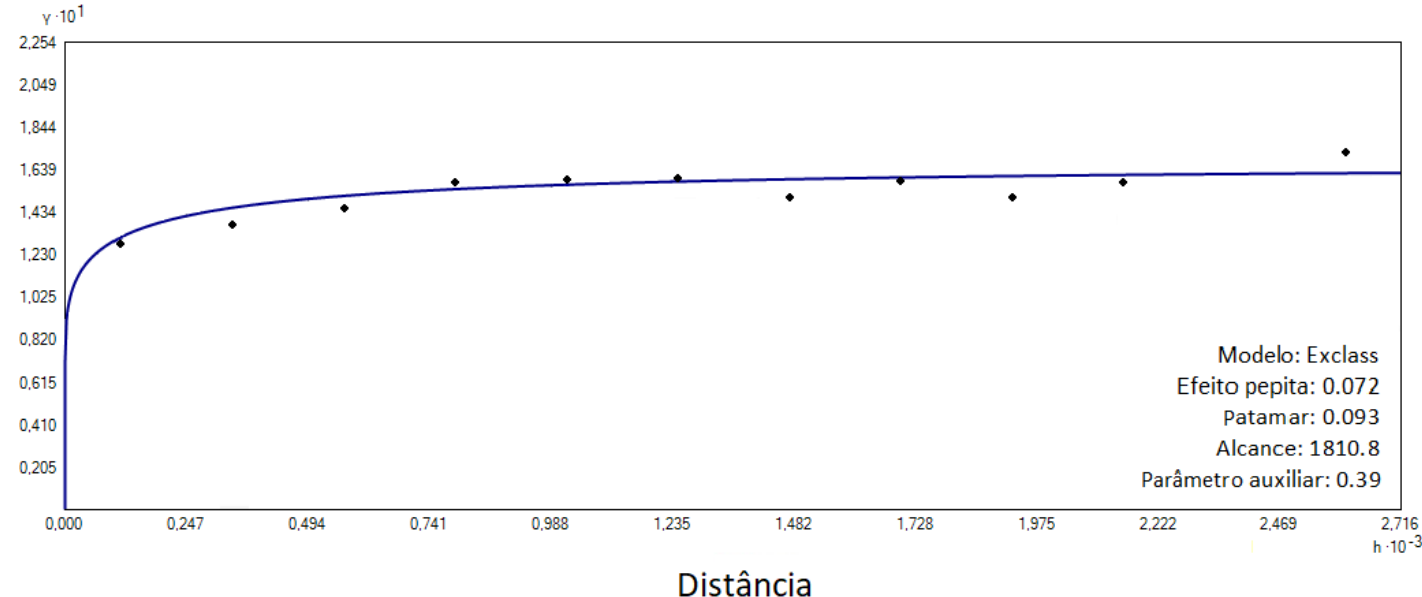

* Onde "Exclass" é abreviatura de Exponential Class/Stable (classe exponencial/estável).

Figura 3 - Semivariograma do nível estático

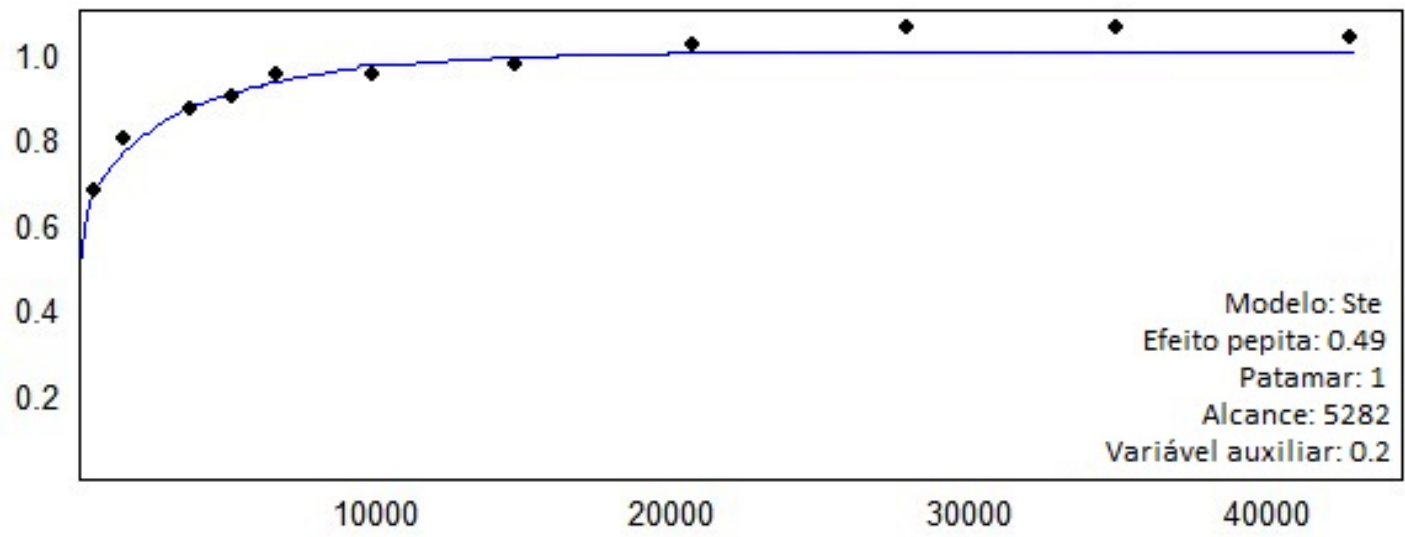

Distância

*Onde “Ste” é abreviatura de Matern, M. Stein's parameterization (Matern, parametrização de M. Stein). 
Figura 4 - Semivariograma da condutividade hidráulica

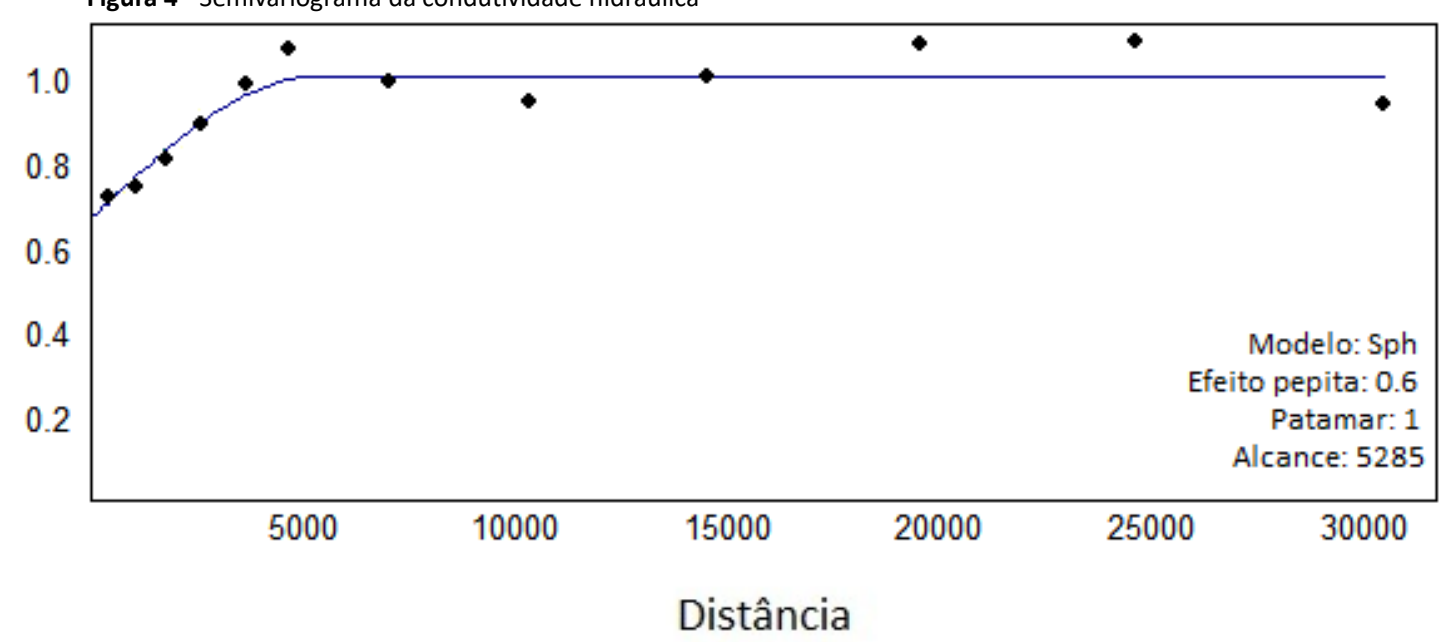

*Onde "Sph" é abreviação de spherical (esférico).

Figura 5 - Krigagem indicativa indicando a probabilidade de a vazão de estabilização estar acima de $20 \mathrm{~m}^{3} / \mathrm{h}$

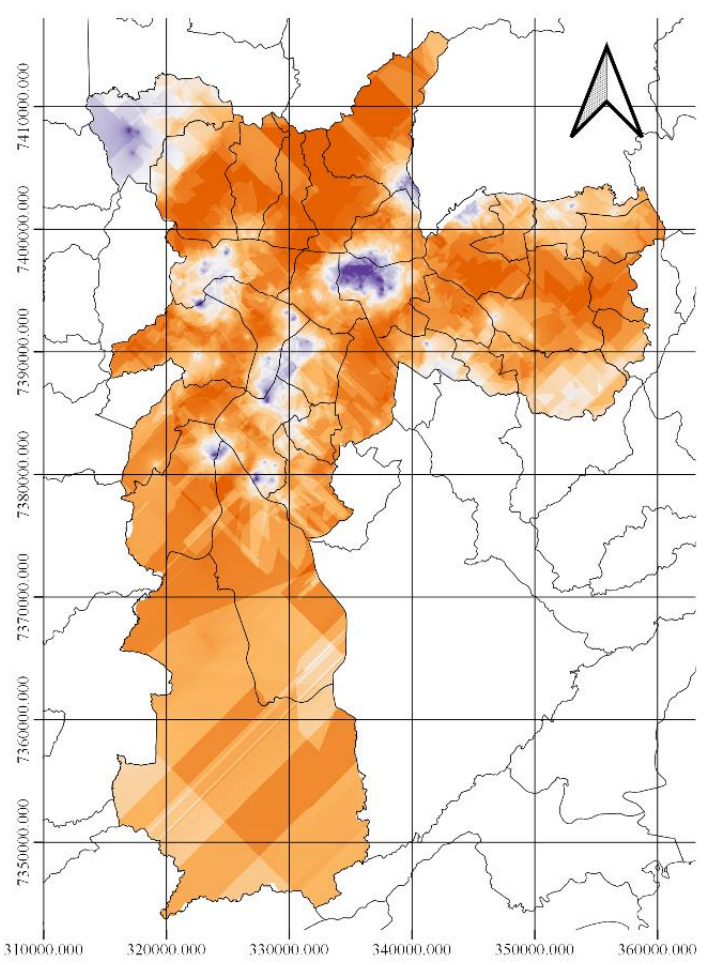

$\square$ Limites Municipais

$\square$ Subprefeituras do município de São Paulo

Probabilidade

$0 \%$

$\square .1 \%-15 \%$

$-15.1 \%-30 \%$

$30.1 \%-45 \%$

$45.1 \%-59.05$
As subprefeituras como Capela do Socorro, Mooca, M'Boi Mirim, Perus e Santo Amaro apresentam maior probabilidade da vazão de estabilização estar acima de $20 \mathrm{~m}^{3} / \mathrm{h}$. Ao passo que as subprefeituras como Casa Verde Cachoeirinha, Freguesia/Brasilândia, Itaquera, Jaçanã/Tremembé, Penha,
Pirituba/Jaraguá, Santana/Tucuruvi apresentam na maioria da área da subprefeitura probabilidade zero de encontrar poços com vazão acima de $20 \mathrm{~m}^{3} / \mathrm{h}$, e é nesse espaço que o raio de segurança é o menor, de $30 \mathrm{~m}$. 
Figura 6 - Desvio padrão da krigagem indicativa da vazão de estabilização acima de $20 \mathrm{~m}^{3} / \mathrm{h}$.

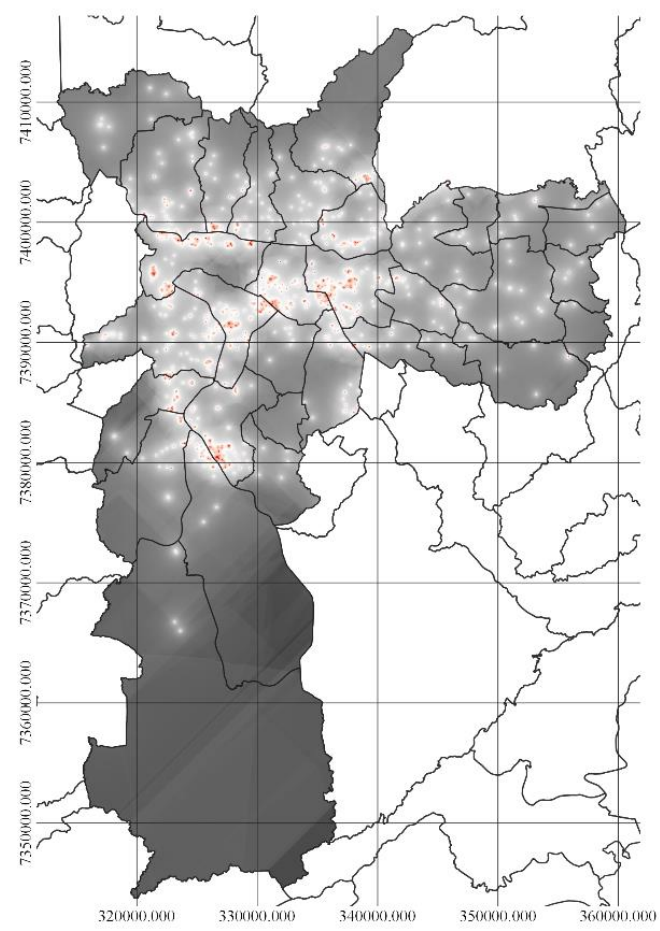

O desvio padrão mínimo da interpolação é $36.18 \%$, isso porque quando analisamos poços existe a possibilidade de poços muito próximos terem paramentos muito diferentes. Vale destacar que a interpolação é mais precisa apenas onde existe maior disponibilidade de informação (Lloyd e Atkinson, 2001). A região mais ao sul do município não há muitos poços conhecidos e, portanto, uma menor precisão da interpolação.

Interceptando os raios de segurança de áreas contaminadas com os poços, tem-se figura 7. Podemos ver que os poços no seu geral estão concentrados na região central do município de São Paulo, nas subprefeituras Aricanduva/Formosa/Carrão, Butantã, Campo Limpo, Casa Verde/Cachoeirinha, Freguesia/Brasilândia, Ipiranga, Jabaquara, Lapa, Mooca, Penha, Pinheiros, Pirituba/Jaraguá, Santana/Tucuruvi, Santo Amaro, Sé, Vila Mariana, Vila Maria/Vila Guilherme, Vila Prudente, todas com alta concentração de poços.

As áreas contaminadas seguem também esse padrão de distribuição mais ao centro do município, e se concentram nas subprefeituras Butantã, Casa Verde/Cachoeirinha, Ipiranga, Lapa, Mooca, Pinheiros, Santana/Tucuruvi, Santo Amaro, Sé, Vila Mariana, Vila Maria/Vila Guilherme. Trata-se de áreas historicamente próximas a estações de trem a partir das quais se desenvolveram distritos industriais no decorrer do século XX (STEFANI, 2007)

Os poços com risco de contaminação estão mais espaçados, mas ainda sim predominam na região central, se encontrando nas subprefeituras Aricanduva/Formosa/Carrão, Capela do Socorro, Casa Verde/Cachoeirinha, Ermelino Matarazzo, Freguesia-Brasilândia, Ipiranga, Lapa, M’Boi Mirim, Mooca, Penha, Pinheiros, Pirituba/Jaraguá, Santo Amaro, São Miguel, $\square$ Subprefeituras do município de São Paulo

Limites municípais

Desvio Padrão

- $36.18 \%$

$36.19 \%-37.75 \%$

$37.76 \%-39.31 \%$

$39.32 \%-40.88 \%$

$40.89 \%-42.44 \%$

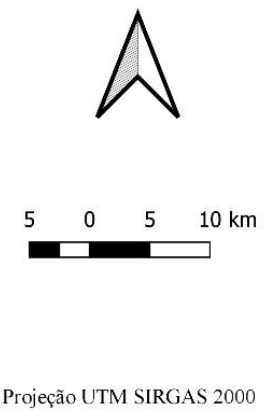

Sé, Vila Mariana, Vila Maria/Vila Guilherme, Vila Prudente. Por predominarem na área central, onde houve menor desvio padrão da krigagem (Figura 6), há uma maior confiabilidade dos parâmetros de interpolação.

O número de poços sob risco de contaminação identificados são 49; o que representa $1,68 \%$ dos poços do município de São Paulo. $65,31 \%$ dos poços em áreas de risco são caracterizados como poços de abastecimento. Isso significa que existem 32 poços usados para abastecimento urbano, doméstico ou industrial com risco de estarem contaminados e representam $1,61 \%$ de todos os poços classificados como de abastecimento. Esse risco pode ser ainda maior devido ao fato de diversos poços no município possuírem deficiências de qualidade técnica construtiva, como com ausência de cimentação, laje de proteção e de tamponamento (PACHECO, 1984).

Os locais onde há maior risco de contaminação de poços foram as subprefeituras Aricanduva/Formosa/Carrão, Capela do Socorro, Casa Verde/Cachoeirinha, Ermelino Matarazzo, Freguesia/Brasilândia, Ipiranga, Lapa, M'Boi Mirim, Mooca, Penha, Pinheiros, Pirituba/Jaraguá, Santo Amaro, São Miguel, Sé, Vila Mariana, Vila Maria/Vila Guilherme e Vila Prudente.

Os poços classificados como de abastecimento se encontram em Pirituba/Jaraguá, Freguesia/Brasilândia, Vila Maria/Vila Guilherme, Lapa, Sé, Pinheiros, Ipiranga, Santo Amaro, M'Boi Mirim, Capela do Socorro, Ermelino Matarazzo, Mooca, Aricanduva/Formosa/Carrão e Vila Prudente.

Interceptando os raios de segurança de áreas contaminadas com os corpos hídricos, tem-se a figura 8. 
Figura 7 - Mapa dos poços com risco de contaminação

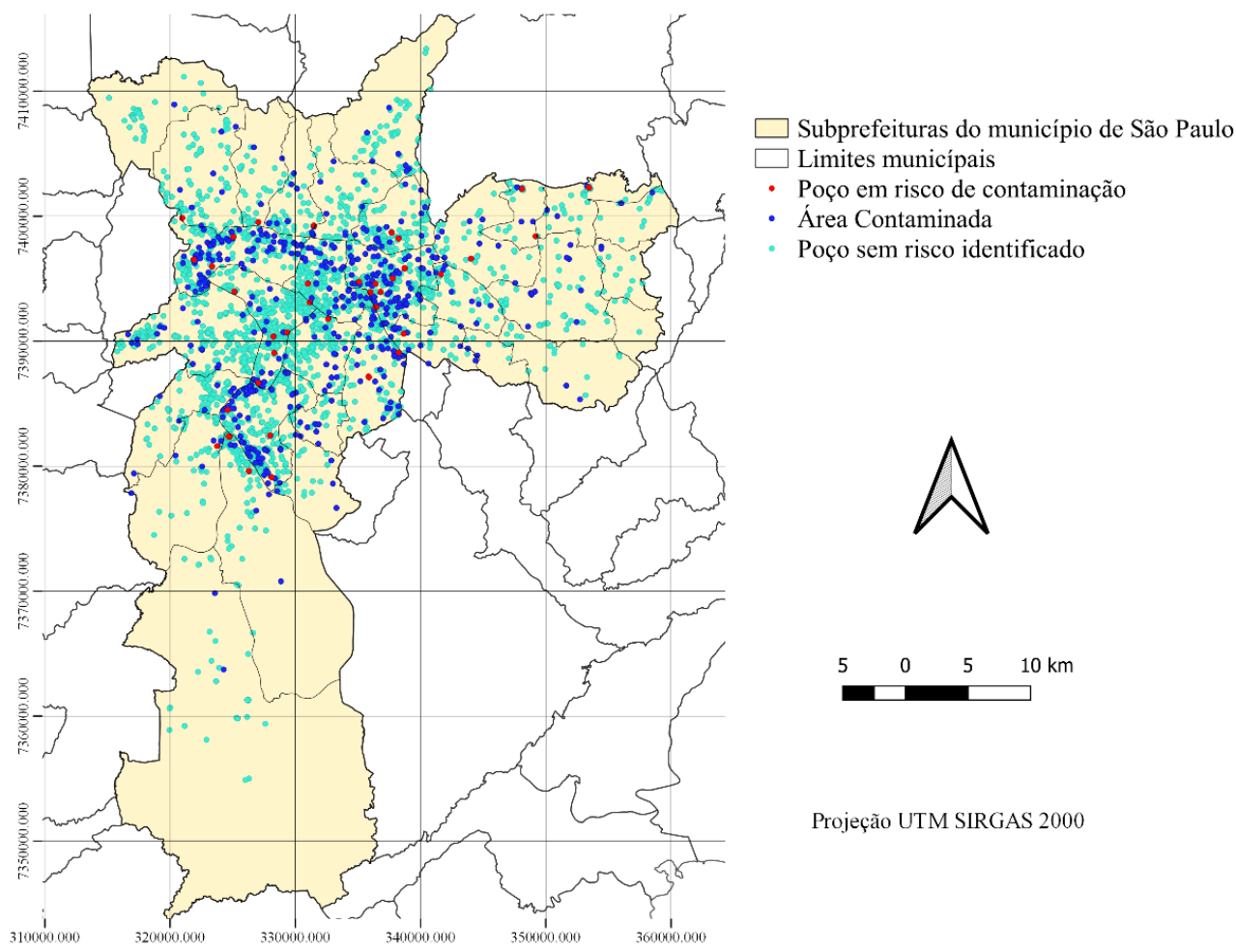

Figura 8 - Mapa do acúmulo de pontos de risco de contaminação na drenagem e nas represas

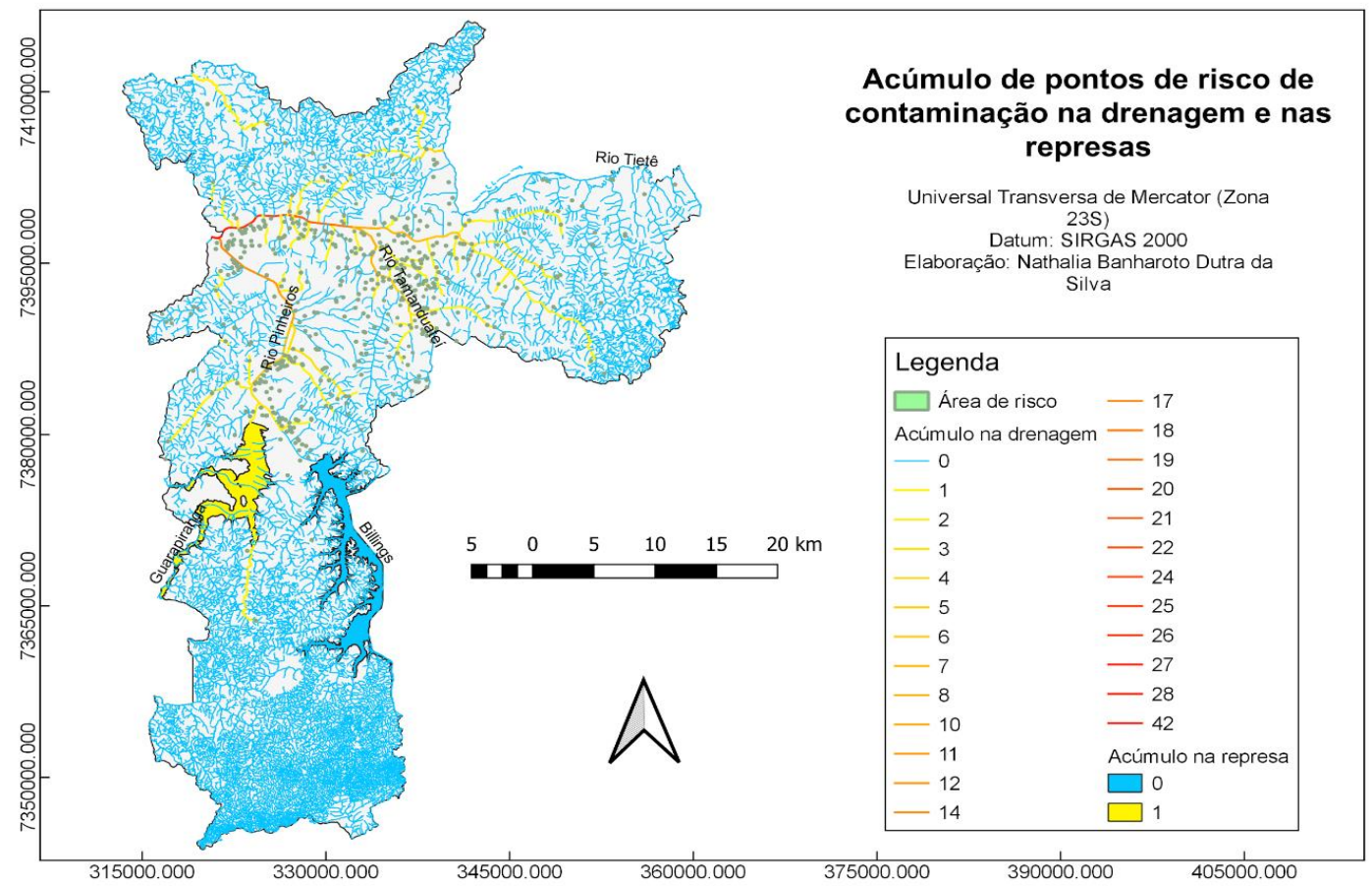

Foram identificados no total 55 pontos de intersecção de áreas contaminadas com cursos d'água no município de São Paulo. Pode-se ver que o Rio Tietê é o que tem maior acúmulo de pontos de risco a montante, e seu máximo atinge 42 pontos de risco de contaminação. Isso se deve também ao fato de que os Rios Tamanduateí e Rio Pinheiros desaguam no Rio Tietê, todos com os maiores números de pontos de risco. Ressalta-se que além das áreas contaminadas avaliadas no presente artigo, o rio Tietê, em seu trecho pelo município de
São Paulo, também apresenta elevada contaminação de nitratos provenientes de fossas e tanques sépticos com vazamento, de acordo com o estudo de Varnier e Hirata (2000).

Os rios e poços contaminados têm ligação direta com o desenvolvimento do município, é principalmente na margem dos rios Tietê, Tamanduateí e Pinheiros que teve a ascensão de São Paulo e o desenvolvimento nessa área trouxe consequências como a contaminação do solo e dos rios. Fica 
nítido que onde se teve mais ações antrópicas há hoje mais pontos de risco.

A Figura 9 mostra o erro padrão do resultado das krigagens ordinárias. Observa-se que o erro padrão foi por volta de 0.80 e 1, e a krigagem de nível estático tem maior área com menos erro, pois esse parâmetro tinha mais dados se comparado à condutividade hidráulica. Isso se deve ao fato de que há um número menor de poços no SIAGAS com a informação sobre diâmetro de tubo, necessário para a estimação da condutividade hidráulica.

Figura 9 - Erro padrão das krigagens ordinárias de nível estático e condutividade hidráulica
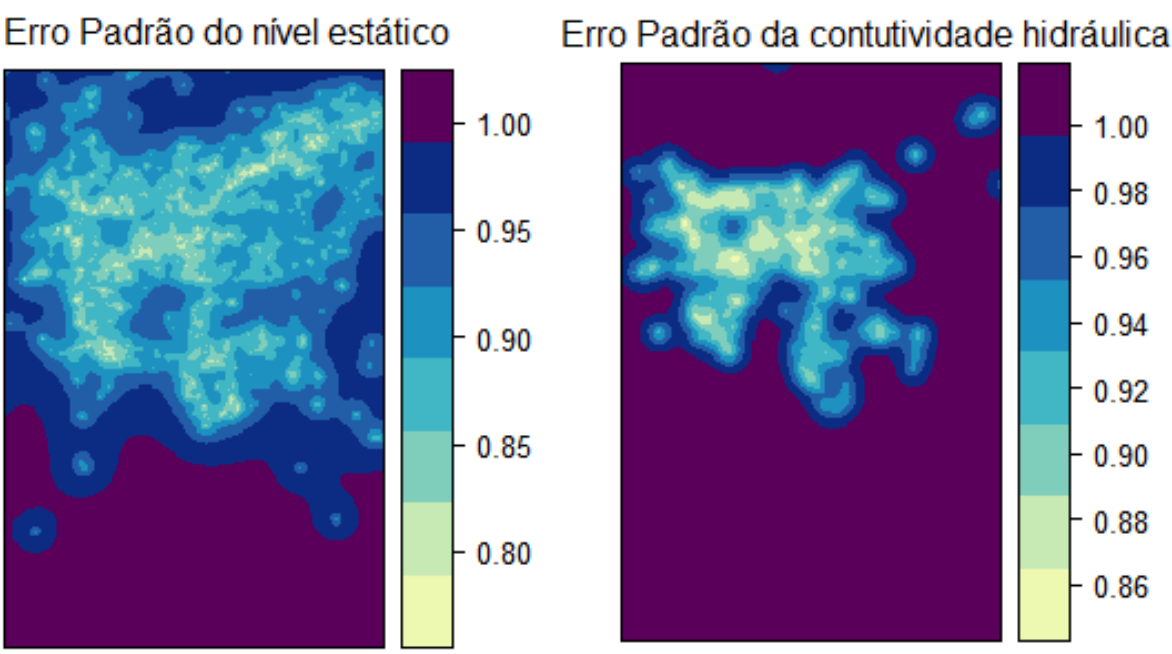

Realizando álgebra de divisão de raster chega-se ao mapa resistência hidráulica e, portanto, valor numérico do Índice de Vulnerabilidade do Aquífero (figura 10). Os valores da resistência hidráulica são muito baixos, e isso indica que existe predomínio da classe de vulnerabilidade "Extremamente Alta" (Tabela 1), que se estende por toda a região do município. Apenas algumas pequenas áreas nas subprefeituras da Lapa, Ipiranga, Vila Prudente e Aricanduva apresentam resistência hidráulica comparativamente maior do que as demais, mas ainda sim dentro da classe de vulnerabilidade "Extremamente Alta". Estas condições de contaminação e vulnerabilidade demonstram que este recurso hídrico pode estar ameaçado diante do uso e ocupação do solo urbano atual, e indicam claramente a necessidade de monitoramento e prosseguimento nos processos de remediação e recuperação destas áreas.

Esses resultados contrastam com o estudo de Conicelli (2014), o qual identificou o aquífero de São Paulo como de classe de vulnerabilidade baixa pelo método GOD (FOSTER et al., 2006). $O$ método GOD usa entradas de dados de profundidade do aquífero, de forma semelhante ao do presente estudo, mas usa pesos referentes às características litológicas e ao confinamento do aquífero, ao passo que aa metodologia AV empregada no presente artigo usa informações de condutividade hidráulica. Além disso, a definição das classes de vulnerabilidade de cada método não é necessariamente compatível entre eles. Ademais, o estudo de Conicelli (2014) foi direcionada a uma região de estudo mais ampla (Bacia do alto-tietê), em que o método GOD forneceu valores para cada unidade aquífera, ao passo que o presente artigo apresenta uma mapeamento mais detalhado do Aquífero São Paulo, inclusive com diferenciação espacial intra-aquífero.

0 resultado da densidade demográfica está na figura 11 , adicionado os pontos de contaminação. É nítido que a as áreas com maior concentração de áreas contaminadas e de poços sobre risco de contaminação também coincide espacialmente com as áreas de maior adensamento demográfico, pois são resultados das atividades e necessidades humanas. Ressalta-se que subprefeituras como Sé, Campo Limpo, Itaim Paulista, Guaianases, Vila Prudente e Sapopemba estão alto grau de adensamento populacional. Pelos dados do IBGE (2010), as subprefeituras com maior número de habitantes são Campo Limpo, M'Boi Mirim, Capela do Socorro, Itaquera e Penha, todos com mais de 500 mil habitantes. 
Figura 10 - Mapa de resistência hidráulica do aquífero e pontos de contaminação próximo a poços e corpos hídricos no Município de São Paulo

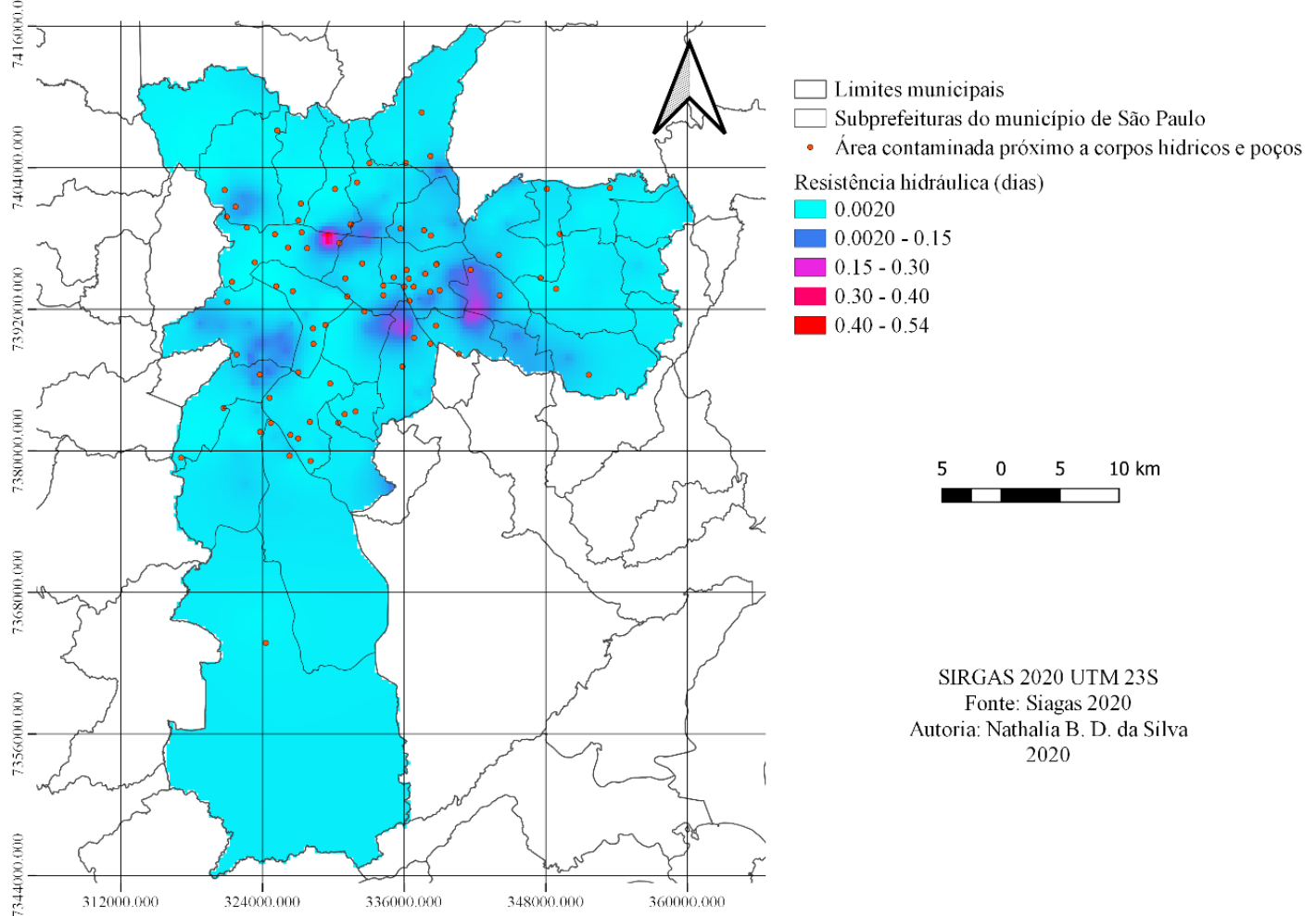

Figura 11 - Mapa de densidade demográfica e pontos de contaminação próximo a poços e corpos hídricos no Município de São Paulo

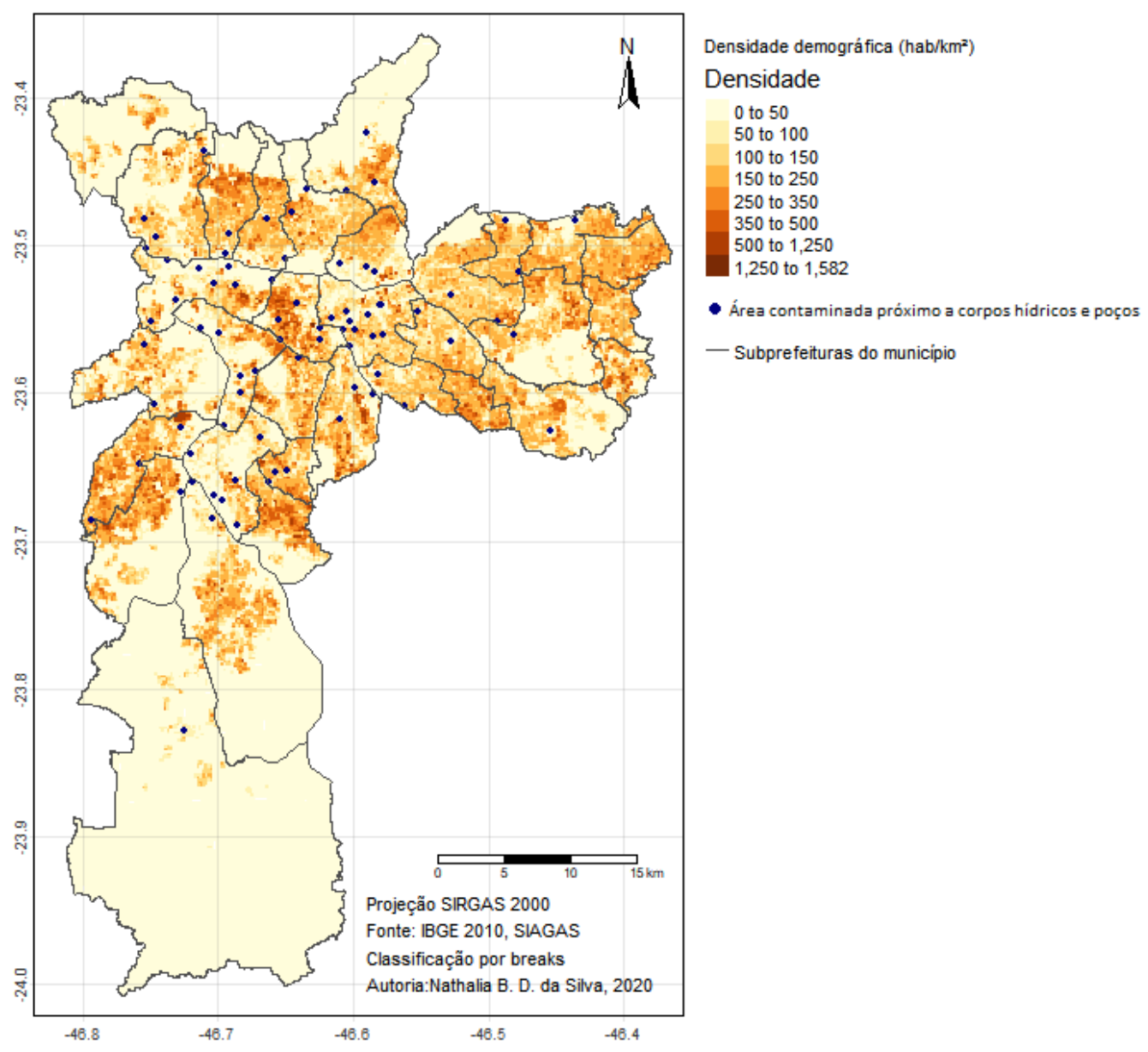


Ressaltam-se os pontos de contaminação em área de maior densidade demográfica e onde há mais intersecções com corpos hídricos, como ao redor dos rios Tietê, Tamanduateí e Pinheiros. Pensando na possibilidade de propagação dos contaminantes, esses seriam os locais a serem priorizados para remediação das áreas contaminadas.

\subsection{Limitações do Estudo e Recomendações}

A metodologia adotada apresenta limitações e simplificações claras. Por exemplo, não se levou em consideração a extensão total de cada contaminação, visto que a base disponibilizada pela CETESB inclui apenas o ponto central. Nesse aspecto, pode haver variações da vazão de estabilização dentro da mesma área contaminada, influenciando o estabelecimento do raio de proteção. Ainda neste tocante, o buffer criado seria ampliado caso partisse da borda dos perímetros das áreas contaminadas, caso essas informações fossem disponibilizadas de forma georreferenciada pela CETESB, ao invés de ser delimitado a partir do ponto central. Ademais, não foram analisadas especificidades de características potencializadoras da propagação de contaminantes, tais como topografia, tipo de solo, tipo e quantidade do contaminante. Apesar dessas limitações, o método empregado serve como uma primeira indicação para priorizar potenciais focos de contaminação e conduzir a estudos mais detalhados.

Como extensão para estudos futuros, é possível incorporar novas variáveis aos métodos de krigagem por meio de técnicas de cokrigagem e regression-kriging, que permitem se utilizar de informações de variáveis auxiliares. Além das camadas de informações geradas por krigagem (como o Índice de Vulnerabilidade de Aquíferos), seria possível também uma abordagem de ponderação multicriterial para combinar outras informações em um indicador único de risco, integrando outras informações ambientais pertinentes, a densidade demográfica (exposição ao risco) e a densidade de áreas contaminadas próximas a cursos de água.

Ademais, atenta-se que as bases de dados de áreas contaminadas e de poços localizam apenas as informações cadastradas oficialmente. Podem existir diversas outras áreas contaminadas e poços não cadastrados, levando a outros riscos de contaminação não mapeados. Não obstante, considerando as bases pontuais como amostras de um universo maior, é provável que os demais pontos não cadastrados se distribuam com padrão espacial semelhante, concentrando-se nas subprefeituras já apontadas como prioritárias. Como diretiva para políticas públicas, uma maior cobertura e cadastramento de áreas contaminadas e poços poderia trazer maior confiabilidade para os métodos de interpolação e, consequentemente, para a avaliação dos riscos de contaminação das águas.

A metodologia desenvolvida neste estudo pode ser replicada em outras regiões, contando que tenham informações sobre as áreas contaminadas, poços e corpos hídricos. A base de áreas contaminadas da CETESB abrange todo o Estado de São Paulo, e as indicações de raios de proteção do IG (2010) também abrangem todos os aquíferos do Estado, portanto a metodologia poderia ser facilmente expandida para a escala de análise estadual. A base de dados do SIAGAS recobre todo o território brasileiro, embora também possa ser possível utilizar bases de dados espaciais de outorgas de água subterrânea e superficial dos órgãos de gestão de recursos hídricos estaduais e federal (Agência Nacional de Águas - ANA).

\section{CONCLUSÕES}

Ao utilizar as ferramentas de geoprocessamento para analisar as intersecções entre pontos de contaminação e poços e corpos hídricos, além de considerar a vulnerabilidade das águas subterrâneas e a exposição da população à contaminação, tornaram-se mais claros os pontos que precisam ser priorizados, por apresentarem maior potencial de risco para a saúde humana. A região central do município de São Paulo, especialmente nas subprefeituras de Mooca, Sé e Lapa, apresentou maior número de áreas contaminadas próximas a poços e cursos d'água, com uma vulnerabilidade muito alta de contaminação dos aquíferos e uma grande exposição devido à elevada concentração populacional.

Pensando na possibilidade de propagação dos contaminantes, os locais a serem priorizados para remediação das áreas contaminadas devem ser aqueles onde há maior risco de contaminação de poços e áreas onde há mais intersecções com corpos hídricos, como ao redor dos rios Tietê, Tamanduateí e Pinheiros. Dos 518 pontos de contaminação, 81 estão próximos a poços e corpos hídricos e por isso devem ser priorizados, especialmente nos casos de poços utilizados para abastecimento humano.

Os resultados desse estudo podem ser úteis tanto para os órgãos ambientais quanto para os usuários de recursos hídricos, inclusive os moradores dessas regiões sob risco. Assim como também podem ser importantes para empresas que desejam instalar empreendimentos próximos, empresas financeiras avaliarem o risco, dizer se é seguro ou não a coleta de recursos hídricos de poços, rios e lençóis freáticos, entre outras medidas e também podem ser usados para gerenciamento da remediação das áreas contaminadas.

\section{REFERÊNCIAS}

ABGE - ASSOCIAÇÃO BRASILEIRA DE GEOLOGIA DE ENGENHARIA. Ensaios de Permeabilidade em solos: orientações para a sua execução em campo, 1996.

AHMADI, S.H., SEGHAMIZ, A. Application and evaluation of kriging and cokriging methods on groundwater depth mapping. Environ Monit Assess, v. 138, p. 357-368, 2008. https://doi.org/10.1007/s10661-007-9803-2

ANA - Agência Nacional de Águas. Panorama da qualidade das águas subterrâneas no Brasil. Brasília: ANA, 2007.

BRILHANTE, O.M.; CALDAS, L.Q.A. Gestão e avaliação de risco em saúde ambiental. Rio de Janeiro: Editora FIOCRUZ, 1999. https://doi.org/10.7476/9788575412411

CABRAL, J. J. S. P. O movimento das águas subterrâneas. In: FEITOSA, F. A. C et al. (ed.) Hidrogeologia: conceitos e aplicações. $2^{a}$ ed. Rio de Janeiro: CPRM, p. 77-94, 2008.

CAMARGO, E.C.G. Geoestatística: fundamentos e aplicações. In: CÂMARA, G., MEDEIROS, J. S. (eds.) Geoprocessamento para projetos ambientais. São José dos Campos: INPE, 1998. 
CAMARGO, E.C.G., FUCKS, S.D., CÂMARA, G. Análise espacial de superfícies. In: DRUCK, S.; CARVALHO, M.S.; CÂMARA, G.; MONTEIRO, A.V.M. (eds). Análise espacial de dados geográficos. Brasília, EMBRAPA, p.79-122, 2004.

CETSB, GTZ. Manual de gerenciamento de áreas contaminadas. 2. ed. São Paulo: CETESB, 2001.

CETESB. Ficha de Informação Toxicológica (FIT). Divisão de Toxicologia, Genotoxicidade e Microbiologia Ambiental, 2020. Disponivel

em: https://cetesb.sp.gov.br/laboratorios/servicos/informacoestoxicologicas/. Acesso em: 6 jul. 2020.

CETESB. Relação de áreas contaminadas e reabilitadas no estado de São Paulo, 2019. Disponível em: https://cetesb.sp.gov.br/areas-contaminadas/relacao-deareas-contaminadas/. Acesso em: 6 jul. 2020.

CONICELLI, B.P. Gestão das águas subterrâneas na Bacia Hidrográfica do Alto Tietê (SP). São Paulo: Tese (Doutorado)Universidade de São Paulo. Programa de Pós-Graduação emem Recursos Minerais e Hidrogeologia, 2014

DRUCK, S.; CARVALHO, M.S.; CÂMARA, G.; MONTEIRO, A.V.M. (eds). Análise espacial de dados geográficos. Brasília: EMBRAPA, 2004.

DYMINSKI, A. S. Contaminação de solos e águas subterrâneas. Curitiba: UFPR, 2006. Disponivel em: http://www.cvs.saude.sp.gov.br/up/Contaminacao\%20de $\% 2$ Osolos.pdf. Acesso em: 6 jul. 2020.

FELGUEIRAS, C.A., DRUCK, S., MONTEIRO, A.M.V., 2002. Análise espacial de superfícies: o enfoque da geoestatística por indicação. In: DRUCK, S.; CARVALHO, M.S.; CÂMARA, G.; MONTEIRO, A.V.M. (eds). Análise espacial de dados geográficos. Brasília: EMBRAPA, 2004.

FETTER, C.W. Contaminant hidrogeology. New York: Macmillan Publishing Company, 1993.

GOVERNO DO ESTADO DE SÃO PAULO. Decreto 32955/91 | Decreto $n^{\circ} 32.955$, de 7 de fevereiro de 1991. Disponivel em: https://governo-

sp.jusbrasil.com.br/legislacao/183184/decreto-32955-91. Acesso em: 28 ago. 2019.

GOVERNO DO ESTADO DE SÃO PAULO. Modelo digital de elevação do Estado de São Paulo. Disponível em: http://www.cati.sp.gov.br/portal/produtos-e-

servicos/publicacoes/acervo-tecnico/modelo-digital-de-

elevacao-do-estado-de-sao-paulo. Acesso em: 19 de jul. 2019.

GUIGUER, N.; KOHNKE, M. W. Métodos para determinação da vulnerabilidade de aquíferos. In: CONGRESSO BRASILEIRO DE ÁGUAS SUBTERRÂNEAS,12., 2002. Anais [...]. 2002, p.4-5

GUNDOGDU, K.S., GUNEY, I., Spatial analyses of groundwater levels using universal kriging. Journal of earth system science, v. 116, n. 1, , p.49-55, 2007. https://doi.org/10.1007/s12040-007-0006-6

HABERMANN, M.; GOUVEIA. Requalificação urbana em áreas contaminadas na cidade de São Paulo. Estudos Avançados, v. 28, n. 82, p. 129-137, 2014. https://doi.org/10.1590/S010340142014000300008
HIEMSTRA, P. Package ‘automap'. CRAN. 2015. Disponível em: https://cran.r-

project.org/web/packages/automap/automap.pdf. Acesso em: 6 jul. 2020.

INSTITUTO BRASILEIRO DE GEOGRAFIA E ESTATÍSTICA - IBGE. Área territorial brasileira. Rio de Janeiro: IBGE, 2018.

INSTITUTO BRASILEIRO DE GEOGRAFIA E ESTATÍSTICA - IBGE Diretoria de Pesquisas. Coordenação de População e Indicadores Sociais. Estimativas da população residente com data de referência $1^{\circ}$ de julho de 2019. Rio de Janeiro: IBGE, 2019.

INSTITUTO BRASILEIRO DE GEOGRAFIA E ESTATÍSTICA - IBGE. Grade estatística. Rio de Janeiro: IBGE, 2016. Disponível em: ftp://geoftp.ibge.gov.br/recortes para fins estatisticos/grad e estatistica/censo 2010/grade estatistica.pdf. Acesso em: 6 jul. 2020.

INSTITUTO BRASILEIRO DE GEOGRAFIA E ESTATÍSTICA - IBGE. Censo demográfico 2010. Disponível em: https://censo2010.ibge.gov.br/. Acesso em: 6 jul. 2020.

INSTITUTO BRASILEIRO DE GEOGRAFIA E ESTATÍSTICA - IBGE. Malhas digitais. Disponível em: http://mapas.ibge.gov.br/bases-e-referenciais/basescartograficas/malhasdigitais.html. Acesso em: 17 abr. 2019.

INSTITUTO GEOLÓGICO - IG. Roteiro orientativo para delimitação de área de proteção de poços. Cadernos do Projeto Ambiental Estratégico Aquíferos. Secretaria do Meio Ambiente. São Paulo, 2010.

JOHNSTON, K., KRIVORUCHKO, K., LUCAS, N., VER HOEF, J. M. Using ArcGIS geostatistical analyst. Redlands: Esri, 2001.

LLOYD, C.D., ATKINSON, P.M. Assessing uncertainty in estimates with ordinary and indicator kriging. Computers \& Geosciences, v. 27, n. 8, p. 929-937, 2001. https://doi.org/10.1016/S0098-3004(00)00132-1

MMA - SRHU. Ministério do meio Ambiente - Secretaria de Recursos Hídricos e Ambiente Urbano. Águas Subterrâneas, um recuso conhecido a ser protegido. Brasília, 2007.

MOSLEMZADEH, M., SALARIZAZI, M., SOLEYMANI, S. Application and assessment of kriging and cokriging methods on groundwater level estimation. J Am Sci, v. 7, n. 7, p. 34-39, 2011.

MONTÉS, P., Smoothing noisy data by kriging with nugget effects. In: LAURENT, PJ, LE MÉHAUTÉ, A., et al., eds. Wavelets, images and surface fitting. p.371-378, 1994.

NAKANO, V.; AVILA-CAMPOS, M.J. DEPARTAMENTO DE MICROBIOLOGIA - UNIVERSIDADE DE SÃO PAULO. Metais Pesados: Um Perigo Eminente. Disponível em <http://www.icb.usp.br/bmm/mariojac/index.php?option=co m_content\&view $=$ article\&id=33\&ltemid $=56 \&$ lang $=b r>$.

Acesso 29 de junho de 2020.

OLIVER, M.A., WEBSTER, R., Basic steps in geostatistics: the variogram and kriging. New York, NY: Springer International Publishing, 2015. https://doi.org/10.1007/978-3-31915865-5 
PACHECO, A. Análise das características técnicas e da legislação para uso e proteção das águas subterrâneas em meio urbano (município de São Paulo) . Tese (Doutorado) Universidade de São Paulo, 1984.

PETERSON, R.A., CAVANAUGH, J.E. Ordered quantile normalization: a semiparametric transformation built for the cross-validation era. Journal of Applied Statistics, p. 1-16, 2019. https://doi.org/10.1080/02664763.2019.1630372

PREFEITURA DO MUNICÍPIO DE SÃO PAULO. GEOSAMPA. Disponivel em: www.geosampa.prefeitura.sp.gov.br/PaginasPublicas/_SBC.a spx. Acesso em: 28 nov. 2018.

RICCOMINI, C.; COIMBRA, A. M. Geologia da Bacia Sedimentar de São Paulo. In: FERREIRA, A. A.; ALONSO, U. R.; LUZ, P. L. (Ed.). Solos da cidade de São Paulo. São Paulo: ABMS/ ABEF, 1992. p. 37-94.

ROCHA, G., FERNANDES, A.J., MANCUSO, M.A., CAMPOS, J.E., TAKAHASHI, A.T., ODA, G.H., PERROTTA,.M., SALVADOR, E.D.,et al. Mapa de águas subterrâneas do Estado de São Paulo. In: CONGRESSO BRASILEIRO DE ÁGUAS SUBTERRÂNEAS, 14., 2006. Anais [...]. 2006.

SANTOS, E., UNGARI, H. C. N., SANTOS, M. B. Principais técnicas de remediação e gerenciamento de áreas contaminadas por hidrocarbonetos no Estado de São Paulo. Unicamp: UNICAMP. 2008. Disponível em: https://cetesb.sp.gov.br/escolasuperior/wpcontent/uploads/sites/30/2016/06/Edson_Helio_Matilde.p df. Acesso em: 6 jul. 2020.

SERVIÇO GEOLÓGICO - CPRM. Sistema de Informações de Águas Subterrâneas - SIAGAS. Disponível em: http://siagasweb.cprm.gov.br/layout/index.php. Acesso em: 10 dez. 2018.

SOUZA, N.A. de. Vulnerabilidade à poluição das águas subterrâneas: um estudo do Aquífero Bauru na zona urbana de Araguari, MG. 2009. 9p. Dissertação (Mestrado) Universidade Federal de Uberlândia, Uberlândia. Disponível em: $\quad$ www.repositorio.ufu.br/handle/123456789/14133. Acesso em: 29 ago. 2019.

STEFANI, C.R.B. O sistema ferroviário paulista: um estudo sobre a evolução do transporte de passageiros sobre trilhos Tese (Doutorado) - Universidade de São Paulo, 2007.

VAN STEMPVOORT, D.; EWERT, L.; WASSENAAR, L. AVI: A Method for Groundwater Protection Mapping in the Prairie Provinces of Canada. PPWD pilot project, Sept. 1991 - March 1992. Groundwater and Contaminants Project, Environmental Sciences Division, National Hydrology Research Institute, Saskatoon, 1992.

VARNIER, C., HIRATA, R. Contaminação da água subterrânea por nitrato no parque ecológico do Tietê-São Paulo, Brasil. In: JOINT CONGRESS OF GROUNDWATER, 1., 2000. Anais [...]. 2000.

VASCONCELOS, V.V., KOONTANAKULVONG, S., SUTHIDHUMMAJIT, C., MARTINS JUNIOR, P.P. and HADAD, R.M. Analysis of spatial-temporal patterns of water table change as a tool for conjunctive water management in the Upper Central Plain of the Chao Phraya River Basin, Thailand. Applied Water Science, v. 7, n. 1, p.245-262, 2017. https://doi.org/10.1007/s13201-014-0240-4

YAMAMOTO, J. K.; LANDIM, P. M. B. Geoestatística: conceitos e aplicações. 2. ed. São Paulo: Oficina de Textos, 2013. 214

p. 